\title{
THE MAIN RESULTS' OVERVIEW OBTAINED BY THE METHOD OF AMPLITUDE-INDEPENDENT INTERNAL FRICTION ON METALS AND IONIC CRYSTALS
}

\author{
O.M. Petchenko ${ }^{1}$, G.O. Petchenko ${ }^{1}$, S.M. Boiko ${ }^{2}$ \\ ${ }^{1}$ O.M. Beketov National University of Urban Economy in Kharkiv, Kharkiv, Ukraine \\ E-mail: gdaeron@ukr.net; \\ ${ }^{2}$ M.Ye. Zhukovskiy Kharkiv National Aerospace University, Kharkiv, Ukraine \\ E-mail: svitlanazagreba7@gmail.com
}

There was made the analysis of the main findings obtained in the field of the dislocations' dynamics research using the method of amplitude-independent internal friction on different objects of study - metals and alkali-halide crystals. The results of Granato-Lücke string dislocation theory verification, as well as of Alshits-Indenbom quantum-mechanical theory of dynamic dislocations' damping for above-mentioned materials were considered in the paper. An analytical review of works aimed at the study of relaxation and thermally activated processes in crystals was performed here. Some promising directions for the further experimental work on this problematics there were revealed as a result of the study.

\section{INTRODUCTION}

The authors [1] of the following study offer to your attention the theory that gives us a connection between acoustic descriptions of the crystal (dislocation's attenuation $\alpha$ and decrement $\Delta_{d}$, frequency $f$ and velocity $v$ of ultrasound waves), dynamic ones (coefficient of damping $B$ ) and structural descriptions of the crystal (density of dislocations $\Lambda$ and average effective length of dislocation segment $L$ ). The string model of dislocation, on which the mentioned theory [1] is based, was consistently developed by the authors of works [2-5] and in its eventual variant [1] it gives us a vivid description of several physical processes, related to the mobile dislocations' interaction in a crystal with defects in its structure.

The well-known work [6], in which there was exposed and generalized the hierarchy of phonon mechanisms of dislocations' damping in crystals [7-10], that substantially strengthened a string model [1]. There arised a unique possibility not only to fix the dynamic and structural descriptions' change that appeared in crystals (and played an important role for physics of plasticity and durability) [11], but also to interpret the got results within the framework of dislocations' phonon damping theoretical picture, that is one of the determinant mechanisms of dislocations' damping at their upper-barrier movement for any solids and only one for ionic crystals (as a result of dislocations' damping general constituent narrowing in their interaction with elementary excitations' gas to only one phonon component).

The experiments on dislocation dynamics study were divided $[6,11,12]$ into two basic groups - works with the use of amplitude-dependent internal friction method and other methodologies to study the dislocations (and investigations in area of amplitudeindependent internal friction as well).

The first group of works is very considerable. There're several noticeable reviews and monographs and the substantial volume of both experimental and theoretical material is accumulated [11-43]. The other group of works is presented with a few of experimental and theoretical works by foreign and Ukrainian authors, and the intensity of those papers' publication in special journals now is subzero. Explanation of such two branches' development unevenness in the common methodology is related to satiety of research laboratories by simple enough standard devices, necessary for realization of experiments in area of amplitudedependent internal friction and practically complete absence of unique non-standard experimental devices, necessary for realization the high-fidelity measuring of acoustic descriptions in the amplitude-independent internal friction area of frequencies.

At the same time, the developers of the theory [1] marked that for studying the subtle physical processes related to interaction of dislocations with the stoppers of different physical nature (impurities in samples, radiation and magnetic treatment, plastic flow), and also to the phonon subsystem of the crystal, the amplitudeindependent internal friction area of measuring is best suited, as such, that directly corresponds to the ideology of string model.

Recognizing the high structural sensitivity of the amplitude-dependent internal friction methodology $\left(\alpha \sim L^{4}\right)[1,12]$ to the dislocation mobility impediments in crystals, we nevertheless do not find a sufficient reason to say that this technique is effective for studying the dynamics of dislocations in crystals. By the way, the direct proofs to this statement became the classic works $[6,44,45]$ in which there were presented the comparison of the results got by the amplitude-dependent internal friction methods and methods of amplitudeindependent internal friction, and summed up that the last are an only reliable source to study the processes of dislocations' unpinning from the stoppers of different physical nature as a result of external influence, including thermal activation.

Today there are no works that would summarize the results got in area of amplitude-independent internal friction.

Regarding to the obvious benefits from the new publications of the overview and comparative findings' analysis of dislocations' dynamics research by the 
methods of amplitude-independent internal friction, and to the estimation of further experimental and theoretical works' perspective in the indicated direction, we choose this as the aim of the following article.

\section{MATERIALS \\ AND EXPERIMENTAL TECHNIQUES RESULTS FOR METALS}

Along with the dislocations' dynamic deceleration phonon component in metals, there is an electronic term [6]; so, these investigation objects are interesting in the view of studying the superposition of both phonon and electronic mobile dislocations' damping mechanisms in crystals.

Copper. In paper [46] the results of the dislocation ultrasound losses' study are given in the frequency range $7.5 \ldots 100 \mathrm{MHz}$ in the single-crystals of high-clean copper $(99.999 \%)$ and for the alloy of $\mathrm{Cu}-0.13 \% \mathrm{Mn}$. Authors tried to set temperature dependence of damping coefficient $B$. For they used the early theories of the dynamic dislocations' damping [47-49], they were not succeeded in determining it correctly; however among the positive lines of work it is possible to mark the displacement of resonant maximum to the area of greater amplitudes and less frequencies, and also the monotonous increase of $B$ along with the temperature growth. It is quite possible to consider the work [50] to be a certain addition and continuation of paper [46], because the author of [50] extended the research area concerning copper alloys - $\mathrm{Cu}-\mathrm{Mn}, \mathrm{Cu}-\mathrm{Ni}, \mathrm{Cu}-\mathrm{Ge}, \mathrm{Cu}-\mathrm{Pd}, \mathrm{Cu}-\mathrm{Pt}$. The authors of [51, 52], in their turn, studied the frequency, temperature and orientation dependences of dislocation ultrasound losses on the basis of radiationexposed samples of $\mathrm{Cu}$. They presented an "effective cleanness" of material conception, that changes in the course of samples' radiation treatment, as a result of which the displacement of resonant curves of dislocation decrement $\Delta_{\mathrm{d}}(f)$ toward higher frequencies and less values $\Delta_{d}$ with increase of dose of irradiation was observed. Also, a fundamentally new effect was that all the frequency spectra of dislocation absorption had matching high-frequency asymptotes, which distinguishes the observed effect of irradiation from temperature studies, in which the indicated asymptotes $\Delta_{\mathrm{d}}(f)$ do not coincide for different $T$. It is possible to establish, that in papers $[51,52]$ the consideration of material's radiation treatment is founded as the method of influence on its dynamic and dislocation descriptions; although, the conception of irradiation influence on mobility of dislocations was known far before [53]. On a copper samples were also done three important papers [44, $54,55]$, which became of a fundamental value for generalization of all experimental and theoretical works' array within the framework of theories $[1,6]$. To compare the above-mentioned results obtained on crystals of $\mathrm{Cu}$ and its alloys with different states of the dislocation structure, which did not correspond to each other and to the theoretical data, and in oder to fundamentally test the theories [1], Naundorf and Lücke [44] used the equipment, on which were simultaneously implemented both methods for measuring acoustic characteristics: amplitude-independent and amplitude-dependent meth- od of internal friction. Analyzing the results of a complex measurement, the authors [44] concluded that an attempt to describe the data obtained in the lowfrequency and high-frequency range as a single profile is incorrect and all previous attempts to extrapolate the results of an amplitude-independent measurement area to the low-frequency area are unacceptable. It turned out that there is no single damping mechanism for the kilohertz and megahertz frequency bands and they are not described by a single theoretical profile. According to the authors, it is possible to speak of a generalized profile only in the context of the two profiles' superposition that have the form of curves with a maximum. In this case, the location of the low-frequency profile is overestimated along the axis of the decrement compared to the high-frequency one, which explains the discrepancy in the order of parameter $B$ magnitude in different experiments. It was also noted that high-frequency data is better described by the Granato-Lücke theory than lowfrequency ones. The paper [54] proposed a method for taking into account subtle changes in the process of dislocation absorption of ultrasound during the transition from high to low frequencies based on a study in copper the influence of the dislocation segment length that oscillates in the field of an ultrasonic wave by the value $B$. According to the authors of [54] high-frequency data is more suitable for testing the quantum mechanical theory [6], but data from low frequencies can be processed by extracting the relaxation component from the generally measured $B$ value, as a result of which only viscous component remains that provides dislocation loss in high-frequency ranges. The authors of [54] were the first to formulate the important concept that the constant of dynamic dislocations' damping is a fundamental characteristic of the material, that does not depend on the studied samples' preliminary processing and is determined only by the interaction of mobile dislocations with a gas of elementary excitations. The paper [55] analyzes the entire array of existing at that time metal and ionic crystals' data (in particular, copper data are considered) in order to establish a hierarchy of phonon and electronic mechanisms of dislocations damping, taking place in the investigated crystals. It has been established that for the copper samples studied by different authors, the electronic mechanisms of dynamic braking of dislocations are less effective than phonon ones.

Aluminum. The dominant majority of studies on dislocation kinetics in $\mathrm{Al}$ are performed using methods not related to high-frequency internal friction, which have already been discussed in previous subsections. The existing works $[48,56]$ on the measurement the dislocation absorption of ultrasound in megahertz - the frequency range on $\mathrm{Al}$ (purity of $99.99 \%$ ) causes a number of questions regarding the technology of conducting, data processing and comparison with the theory. In particular, the author of paper [56] made the dubious conclusion that the lengths of the dislocation segments remain almost unchanged when the crystals are deformed. In addition, the authors $[48,56]$ relied on the early theories of dislocations' dynamical damping [47-49], which were not sufficiently developed at that time, and, consequently, the results of their work are, unfortunately, incorrect. Absolute values of $B$, obtained 
on $\mathrm{Al}$ by different methods, are in the range from $5 \cdot 10^{-4}$ to $10^{-6} \mathrm{~Pa} \cdot \mathrm{s}$. It should be noted that the authors [55] used only the precision data obtained from the highfrequency asymptote of the resonance curve $\Delta_{\mathrm{d}}(f)$ for the analysis of existing experimental data on the study of the $B$ magnitude on crystals of $\mathrm{Al}$ within the theory of [6].

Iron. A well-known work [57], which provides a brief description of the study on Fe crystals of various purity degrees, preprocessing and dislocation structure in the form of a technical report. Judging by the theoretical sources $[47,49]$, which are referred to by the authors, their results may raise some questions.

Steel. This early paper (1952) [58], demonstrates the data on impulse absorption measurement in various steel grades. The work has no dislocation orientation, but is interesting in terms of early technology and author's recommendations for acoustic measurements.

Niobium. Mazon and McDonald [59] performed a comprehensive work on samples of $99.98 \%$ niobium with impurities W, Mo, Ta, oriented close to the crystallographic direction $\langle 110\rangle$. The magnitude of the orientation factor was calculated, the elastic modules $C_{11}, C_{12}, C_{44}$ and the module defect velocity, the damping constant and its temperature course were determined. The authors of [59] made no comparisons with the theory [6], and dynamical damping were considered in terms of the Leibfrid's concept [49]. The monotonous decrease in $B$ along with the temperature growth, which qualitatively corresponds to the results of further work on other samples of materials can be noted as an important result of the authors' work.

Antimony. By V.I. Startsev research group [60] on samples of high-purity antimony the study was performed, the results of which were processed within the string dislocation theory [1] and quantummechanical theory [6]. The authors found, that in the investigated temperature interval of $100 \ldots 300 \mathrm{~K}$, for the dynamic damping of dislocations in the studied samples the superposition of the phonon wind and the relaxation of "slow" phonons are responsible, which corresponds to the theoretical predictions of the authors [6]

Bismuth. The authors [61] investigated the frequency and the dislocation absorption of ultrasound amplitude dependences in $99.999 \%$ bismuth in the temperature range $4.2 \ldots 300 \mathrm{~K}$. The high-frequency measurement interval was 7.5..142.5 MHz. Basically, the amplitude dependences of internal friction for different temperatures were studied and their course was analyzed, especially at low temperatures. According to the amplitude-independent internal friction, the authors have quite correctly established the value of $B$ at room temperature.

\section{RESULTS FOR IONIC CRYSTALS}

For ionic crystals, the studies were more intense due to the model of these crystals and the possibility of studying the phonon-dislocation interaction in a pure form (without taking into account the electronic component of the dynamic dislocation damping). Let us consider the main results achieved in studying the dynamics of dislocations in ionic crystals by the method of amplitude-independent internal friction.
NaCl. L.G. Merkulov research group [62-64] studied absorption and ultrasound velocity in the high frequency in ionic crystals. The measuring range of their device was 5..200 MHz. They measured the frequency (in particular for different temperatures), the amplitude and time dependences of the dislocation absorption, and the sound velocity for a number of ionic crystals, including $\mathrm{NaCl}$, on the basis of which the elastic modules of the crystals were calculated. Due to the absence of the Alshits-Indenbom quantum mechanical theory [6], the results [62-64] could not rely on it, but according to the string theory of the model [1], the authors noted some results [28-30], which proved useful in terms of validating the model [1]. The group of Ya.M. Soifer [65, 66] also performed some important work on estimating magnitude $B$ and its temperature variation based on high-frequency measurements in the range of $30 \ldots 150 \mathrm{MHz}$. The works of the authors [6770] contain the results of testing the method of internal friction to study the effects associated with dislocation mobility. The study [68] contains both data on measurements of $B(T)$ and survey data from works [67, $70]$, which contain very interesting results of the world's first dispersion of velocity studies in $\mathrm{NaCl}$ and the effect of radiation exposure on the decrement of dislocation absorption of ultrasound and the defect of the module. The estimates of the absolute value and the temperature variation $B$ performed in these works were obtained with the involvement of early Leibfrid and Mezon's theories of the phonon-dislocation interaction; therefore, unfortunately, they are not completely correct. And at the end of this part of the review we consider the works [71-74] that were made on the multifunctional device [75] by the group of O.M. Petchenko. In these works, based on the velocity and absorption of ultrasound measurement by acoustic methods, the effect of shifting the frequency spectra of the dislocation ultrasound absorption with temperature and deformation was found and the corresponding dependences of the dislocation segment effective length were correctly determined; as a result of which the absolute value of the parameter $B$ and its temperature dependence in the framework of the theory [1] were obtained. The effective phonon mechanisms limiting the mobility of dislocations in the studied $\mathrm{NaCl}$ crystals were established in terms of [6]. It is shown that the value of $B$ does not depend on the density of mobile dislocations, which confirms the authors' opinion [54] that the damping constant $B$ is a fundamental characteristic of the material, which depends only on the interaction of mobile dislocations with the phonon subsystem of the crystal and independent of its dislocation structure. In addition, in papers $[73,74]$ the effect of dispersion of sound waves that was previously considered in $[67,70]$ was studied. Using the capabilities of [1] to determine the parameters $B$ and $L$ according to the measurement of the frequency dependency of the defect module, the authors were able to establish the relationship $B$ and $L$ from $\Lambda$ and compare them with similar dependencies defined on the same samples by another method - descending branches of the frequency dependences $\Delta_{\mathrm{d}}(f)$ for samples with different degrees of preliminary strain. It turned out that the dependencies $B$ and $L$ from density of dislocations 
in crystals $\Lambda$ in [71-74] are qualitatively identical, but quantitatively different, which is a direct confirmation of Naundorf and Lücke works' conclusions correctness [44] about the impossibility of describing the data obtained with high-frequency and low-frequency regions by a single profile.

It is necessary to separately mention a series of works by O.M. Petchenko group [76-79] performed on single crystals of sodium chloride. In these works, for the first time in the world, the effect of the velocity of plastic deformation, the degree of preliminary deformation and the dislocation structure ("forest" dislocation and impurity dislocations pinning centers) on the depth of stress relaxation in studied crystals was investigated; and acoustic methods of investigation were used to indicate relaxation processes (measurements dislocation absorption and ultrasonic velocity), which are too sensitive to the processes of subtle structural changes in crystals. Based on the obtained findings, the values of the effective dislocation segment length in crystals were calculated, which gradually decreased as a result of relaxation processes in crystals. Along with other, authors determined the critical value of the velocity of plastic deformation $\sim 5 \cdot 10^{-6} \mathrm{~s}^{-1}$, in which the depth of relaxation value in crystals was virtually zero, and the dislocations evenly filled the volume of the crystal without formation of slip lines, which is a fundamentally important result for measurements in the amplitude-independent area. It is important, as the authors [6] determined the error of finding the density of dislocations by the method of selective etching (the magnitude of which was considered essential because of the complication of counting the pits of etching in the slip bands) as the only source of errors in the measurements of resonant dislocation losses.

CsJ. In paper [80], the authors studied the effect of temperature in the range of $1.5 \ldots 80 \mathrm{~K}$ on velocity and absorption of ultrasound in deformed and irradiated samples. The reduction of absorption with temperature demonstrates the effect of "freezing" the stoppers on the dislocations, enhancing the effect of deformation and irradiation, which is reflected in the "settling" of the observed curve $\Delta_{\mathrm{d}}(T)$ that occurs through the additional fixing of the dislocation segments by "strong" stoppers (nodes of the dislocation grid) and "weak" stoppers defects of radiation nature. In addition, according to the dependences given by the authors [80] it is evident that the deformation effectively fixes the dislocation segments - the upper curve $\Delta_{\mathrm{d}}(T)$ corresponds to a nonirradiated and undeformed state of the specimen; under it is the curve for the irradiated crystal, and even below is the curve for the deformed one. As for temperature dependences of velocity, then the situation is reversed, that is, all the above dependences, on the contrary, increase with decreasing temperature. This is also qualitatively quite understandable: the lower the temperature, the less notable are the processes of external energy absorption and, accordingly, there should be a higher velocity of sound passage through the crystal. In paper [81], the authors set the temperature course of the damping constant and the average effective length of the dislocation segment. The decrease of $L$ and $B$ with decreasing temperature demonstrates the effects of reducing the dislocation segment due to the reduction of the dislocation thermal decoupling from the stoppers probability and the "freezing" of the phonon gas, respectively. The comparison of the obtained results with the AlshitsIndenbom theory was made and conclusions were obtained regarding the phonon mechanisms corresponding to the dynamic dislocations damping in CsJ samples. Investigation of $B(\Lambda)$ dependence was traditionally performed by the O.M. Petchenko research group on all ionic crystals, but not for CsJ. In works [82-84] made by the research group of O.M. Petchenko, a vivid example of using the method of internal friction to study the processes of relief formation in samples was set. The authors [82-84] for the first time in the world used ultrasonic sounding of crystals at the same time as their load to study the subtle relaxation processes in crystals that continue to reach the relief boundary. The experiments were carried out on crystals with different angles of divergence relative to the crystallographic direction $\langle 100\rangle$ (the direction prohibited for deformation CsJ samples) in which the influence of temperature and rate of deformation on the processes of relief formation boundary was investigated. It is shown that the increase in temperature (starting from $400 \mathrm{~K}$ ) and the angle of deformation reduces the value of the dropping boundary (at a fixed rate of deformation). For the first time, the processes preceding the dropping have been demonstrated. Experiment technology was as follows. Samples were loaded stepwise, and after each stop rod tensile machine, fixed mechanical relaxation in the form of attenuation decay $\Delta \alpha$. For the first time (with the load level increasing) was observed the increase of $\Delta \alpha$. When the load level exceeded the critical value $\sigma>0.5 \sigma_{c}$, (where $\sigma_{c}-$ relief formation boundary in crystals), there were observed the decrease in $\Delta \alpha$ by the law, that previously provided its increase. Only after the collapse of the relaxation process $(\Delta \alpha \rightarrow 0)$ the dropping process began. In this case, the non-monotonic behavior of $\Delta \alpha$ showed how the crystal was developing the process of relaxation, and how it was trying to find a way to get rid of external loads and to reduce its internal energy. As all the possibilities of relaxation the reduction of mechanical stress were exhausted, it began to accumulate itself and the crystal went out to the level of stress required for the relief formation. One can see that internal friction makes it possible to investigate the subtle structural processes in crystals at a time when traditional methods are completely unsuitable. In the works [86, 87], the same authors demonstrated one more of the possibilities provided by the method of internal friction - the conduction of thermo-activation analysis in the quasi-elastic region of deformation. It is worth noting that studying in this way the thermoactivating parameters and the force law of the dislocation interaction with the stoppers was conducted the second time in the world. The authors of the first work on copper [88] are Kryshtal, Golovin and Troitsky, which created and experimentally tested the technique of studying the type of stoppers on dislocations in crystals on the base of results of the 
experiment, in which the simultaneous influence of temperature and elastic loading on the dislocation absorption of ultrasound is recorded. After the publication of works $[85,86]$, the approbation of the method [87] was extended to the ionic crystals, that was of a fundamental importance.

KCl. Among the early works on the study of elastic, dynamic and dislocation characteristics of potassium chloride crystals by high-frequency pulsed echo-method (amplitude-independent area) it is necessary to note the works [46, 62]. The velocities' values for ultrasound waves in the longitudinal and transverse directions $<100>$ and $<110>$ and the elastic modules $C_{11}, C_{12}$, and $C_{44}$ were investigated in [62]; the constant $B$ and the effect of radiation on it (with the calculation of the volume concentration $N_{f}$ of the color centers, arising in $\mathrm{KCl}$ under the influence of irradiation) as well as the effective length of the dislocation segment $L$ were determined in [46]. But a serious analysis of dislocation losses based on the phonon-dislocation interaction in these works was not made (quantum-mechanical theory [6] appeared much later), but even such preliminary data were of unquestionable value. Further the certain attempts by the authors of $[88,89]$ were made to establish the value of the damping constant in $\mathrm{KCl}$ and the effect of the previous deformation of the samples. The results obtained by them can also be evaluated positively in general, although they need to be reviewed - both in terms of experimental technology and in terms of theoretical processing and description of data. In the O.M. Petchenko and colleagues' works [90-92] was studied the influence of temperature and deformation on the behavior of the dependences $\Delta_{\mathrm{d}}(f)$ and separately established the temperature dependence of the elastic modules $C_{11}, C_{12}$, and $C_{44}$ on the basis of measuring the velocity of ultrasound. The processing of the results was carried out within the framework of the theory [1], as a result of which the dependences $B$ and $L$ of $A$ and $T$ were established. The phonon mechanisms' estimations that were appropriate for reducing dislocation mobility were carried out in terms of the theory [6]. It can be stated that the mentioned series of papers [90-92] almost completely covered all the issues concerning the dislocations' damping in potassium chloride at their upper-barrier movement. However, there remained not fully clarified the question regarding the findings obtained by the authors [90], based on $B(\Lambda)$, which vary somewhat depending on the degree of samples' preliminary treatment, which requires additional control measurements for the verification. Later, by the authors of [93] the further research on this issue (on single crystals of potassium chloride of the same series) was carried out and they proved the independence of $B(\Lambda)$ in the whole interval degrees of preformed samples. It turned out that in paper [90], at calculating the value of $B$, an inappropriate way of processing experimental data by $\Delta_{\mathrm{d}}(f)$ was used. These curves were rebuilt in dependence $\Delta_{\mathrm{d}}=\Psi(1 / f)$, and the value of $B$ was determined on the data of the rectilinear sections' inclination of these reciprocal dependences, which does not meet the requirements of the theory [1], where the calculation of parameter $B$ should be carried out at the high-frequency asymptote of the dislocation decrement frequency spectra. In the works [94, 95] a thermoactivation analysis of the process of dislocations' unpinning from point stoppers in crystals was carried out within the framework of the method [87].

LiF. Some of the first attempts at dynamic dislocation measurements were made by the authors of $[67,96]$. These works were performed quite carefully, but comparing of the results with phonon theories was complicated. In the work of Mitchell [96], from the graph given by him, it is clear that his data do not coincide neither with the theory of Leibfrid, nor with Mezon's one. In the paper [67], the authors attempted to establish the temperature course $B$, and even compare it in the dimentionless coordinates with the theory [6]. But, due to the fact that their data on one curve virtually overlapped the points for both $\mathrm{NaCl}$ and $\mathrm{LiF}$ (although the Debye temperatures for these crystals differ almost twice), there is a great doubt about the reliability of these data. If we take into account the technique used to allocate the dislocation contribution in the general absorption by irradiating samples of $\gamma$-quanta from the $\mathrm{Co}^{60}$ source to a total dose of $\sim 10^{8} \mathrm{rad}$ (it means subtracting of some average dislocation less background accepted for crystals of the whole series), the causes of such errors become clear. The authors of [97-99] carried out the whole cycle of acoustic measurements in the amplitude-independent area, including the measurement of dislocation absorption and the velocity of ultrasound, on the basis of which elastic modules were calculated, necessary for the correct finding of the parameters $B$ and $L$. According to the results of the research, they established the dependences $B(T)$ and $B(\Lambda)$ and determined the phonon mechanisms responsible for dislocations drag in $\mathrm{LiF}$ at their upperbarrier movement. Weak dependence on the density of dislocations of value $B$, as in [90], required further refinement. In [100], this uncertainty was eliminated and the independence of $B(\Lambda)$ proved.

The separate result obtained for crystals of lithium fluoride in the direction of studying dislocation dynamics by the method of amplitude-independent internal friction has become a series of recent papers [101-109]. In the studies [101-106] the pulsed echo method was used to determine the effect of $x$-ray irradiation with doses up to $1000 \mathrm{R}$ on the localization of a damped dislocation resonance in the frequency range of $22.5 \ldots 232.5 \mathrm{MHz}$ and at a temperature $T=300 \mathrm{~K}$ on $\mathrm{LiF}$ single crystals preformed to $\varepsilon=0.3$, $0.4,0.65,1$, and $1.5 \%$. It was found that a gradual increase in the degree of x-ray of crystals causes the appearance of two effects: a monotonous shift of the resonant maximum parameters towards high frequencies and the process of quenching the amplitude of the dislocation resonance. The obtained results confirmed the validity of theoretical predictions made in [52] regarding the behavior of the parameters of the $\Delta_{d}(f)$ curves' resonant maximum - the frequency $f_{m}$ and the maximum decrement. Also, the dependences of the dislocation segment average effective length on the irradiation time for crystals with different $\varepsilon$ were determined. The decrease of the parameter $L$ with the increasing radiation dose is caused by the blocking of 
mobile dislocations by pinning centers, which appear after an increase in the degree of $x$-ray exposure. On the basis of the obtained dependence, the monotonous displacement of the resonance maximum parameters in the given interval of radiation doses is explained. It is shown that the length of the dislocation segment decreases with an increase in the dose of radiation according to the law provided by the authors of the theory [52], which reflects the processes of mobile dislocations' pinning in crystals by radiation defects. In addition, the effect of crystals' irradiation to $0 \ldots 400 \mathrm{R}$ doses was observed on the studied independence of the dislocations' dynamic damping coefficient $B$ from the density of dislocations in LiF crystals. The established immutability of the characteristic $B(\Lambda)$ from the time of $x$-ray exposure is $0 \ldots 60 \mathrm{~min}$ is a complementary and vivid confirmation that the coefficient $B$ is a fundamental characteristic of the crystal and the dislocations' damping dynamic is determined only by dissipative processes in the phonon subsystem of the crystal [54].

In papers [101-108], the effect of low doses of x-ray irradiation on the ultrasonic velocity dispersion $v(f)$ in the frequency range $7.5 \ldots 232.5 \mathrm{MHz}$ in samples with a residual strain of $0.65 \%$ at $T=300 \mathrm{~K}$ was determined by acoustic methods for LiF crystals. It was determined that the previous deformation of the samples leads to the emergence of a clearly defined dispersion region on the $v(f)$ curve, which changes for non-deformable samples according to linear law. The dispersion shift of the $v(f)$ curve is especially noticeable at low frequencies, where the process of the elastic energy of ultrasonic waves scattering by long dislocation loops is enhanced. Further irradiation of LiF crystals with X-rays reduces the dispersion region and returns the shape of the $v(f)$ curve to its original form, which is explained by the pinning of dislocations with radiation-induced defects and the decrease in the modulus defect. The influence of the irradiation time on the amplitude and frequency localization of the modulus defect in LiF crystals has been established. Based on the measured dispersion curves $v(f)$, the functional dependences of the dynamic viscosity coefficient $B$, the average effective length of the dislocation loop $L$, and the density of dislocations $\Lambda$ on the time of x-ray irradiation are calculated. The independence of the parameter $B$ from the time of exposure in the range of $0 \ldots 120 \mathrm{~min}$ is established, and it confirms clearly the pattern that we studied using another method: measuring the dislocation loss of ultrasound in an amplitude-independent area. Anyway, the comparison of the results from [101-108], obtained by means of two methods based on measurements in the ranges of low and high frequencies on the same crystals has been made. It was shown that both methods allow the same qualitative physical mapping to be obtained, but the quantitative results in the case differ for about an order of magnitude, which indicates that the dislocation losses in the crystal can't be described in the range of low and high frequencies by a single mechanism, as it is suggested by the authors of work [44].

An extra confirmation of the predictions' [44] validity is the work [109], in which LiF crystals of the same series that were used in [101-108] implemented another independent algorithm for calculating the dynamic and structural characteristics, proposed by the authors of the string dislocation theory [1], in which the data are taken from measurements of absorption and relative ultrasound velocity in a sample at a fixed frequency.

KBr. First in the context of applying the methods of internal friction for studying the dynamic and structural parameters of a crystal, we must recall the early work made by the group of V.I. Startsev [110], although it, strictly speaking, belongs to the amplitude-dependent field of measurement $(77.7 \mathrm{kHz})$. Despite the overvalued estimates of $B$ obtained by the authors of this work, one can note the high level of the article both in terms of the experiment and in terms of physical discussion of the findings obtained. It should also be borne in mind that at the time of this work publication there was no theory [6], and the rapid development of methods of internal friction was only beginning. The single basis for the authors of [110] could only be the data on the individual dislocations' mobility, which at that time, although applicable, were not still verified regarding their reliability by the subsequent work of S.V. Lubenets [45]. The further study on $\mathrm{KBr}$ is reflected in [111117]. In papers [112-117], in the framework of the amplitude-independent internal friction method, the comprehensive work was performed on $\mathrm{KBr}$ (on samples of one series) to study the temperature behavior (in the temperature range $77 \ldots 300 \mathrm{~K}$ ) of elastic modules and frequency spectra of dislocation absorption, as well as the study of the dislocation structure of the samples effect on the behavior of the $\Delta_{\mathrm{d}}(f)$ curves. According to the results of the research, the independence of $B$ from $\Lambda$ for various $T$, as well as temperature variations of $B(T)$ for samples with different $\Lambda$ and contributions of the phonon wind mechanisms and "slow" phonons' relaxation into dynamic dislocations' damping in potassium bromide were also established. In addition, in paper [114], in the framework of the method [88] and in the continuation of its testing $[86,87]$ on ion crystals, the authors performed a thermal activation analysis of the process of unpinning dislocations in $\mathrm{KBr}$ and $\mathrm{KCl}$ based on studying a series of curves $\alpha_{d}(\sigma)$ for various $\mathrm{T}$ of the interval $300 \ldots 430 \mathrm{~K}$. The operating frequency of ultrasonic measurements was 7.5 MHz. The average effective length of the dislocation segment, the cell size of the dislocation grid, and the binding energy of the dislocation with the stopper were also estimated. Based on the study of such characteristics as the activation energy and the activation volume in a wide range of elastic loads, the authors established empirical force laws of the dislocations' interaction with active centers of pinning in the studied crystals. After the adjustment of the activation volume empirical dependence on the loading in dimensionless coordinates and after their comparison with existing various theoretical patterns' types of dislocation interaction with stoppers [118], the authors made the conclusions regarding possible types of stoppers that can perform a sticky action on dislocations.

Summing up the consideration of the results obtained by the method of amplitude-independent internal friction, we should note the recent papers $[119,120]$, in which the optical method [121-126] was used simultaneously with the above mentioned one, which made it 
possible to determine the nature of x-ray pinning centers in the crystals under study.

\section{CONCLUSIONS}

On the basis of the conducted review, where the current state of the dislocation dynamics investigation by the method of amplitude-independent internal friction was discussed, it can be stated that the perspective directions for further work in the field of ionic crystals' studying are as follows.

1. Carrying out the research on the magnetic field's effect on the frequency spectra localization of the dislocation ultrasound absorption in crystals. The presence of modern works [33-42] convincingly confirms the fact of the dislocation kinetics high sensitivity to the degree of magnetic treatment of samples. Applying the data of this experiment in the framework of Granato-Lücke theory will allow us to determine the magnetic processing effect on the dynamic and structural characteristics of crystals; and by comparing these data in terms of the AlshitsIndenbom theory with those, obtained earlier, (with a change in temperature and degree of preliminary deformation and $x$-irradiation) we'll be able to draw important conclusions about the activation of the dislocation movement process by a magnetic field.

2. It'll be useful to perform the thermal activation analysis within the framework of the method [87] for still unexplored ionic crystals, primarily $\mathrm{NaCl}$. The low Debye temperature for the crystals has been already studied on such Alkali-halides as: $\mathrm{CsI}, \mathrm{KBr}, \mathrm{KCl}$, that made it possible to study the unpinning processes at not very high temperatures (up to $\sim 430 \mathrm{~K}$ ). Shifting researchers' attention to crystals with higher Debye temperatures will lead to the need of upgrading the experimental equipment for operating at higher temperatures.

3. The study of the processes of relaxation and relief formation in crystals by the method of amplitudeindependent internal friction was started by the authors [76-79, 82-84]. These works are the only examples in the world to conduct such research, therefore the relevance of further work in this direction remains rather high.

\section{REFERENCES}

1. A. Granato, K. Lücke. String model of dislocation and dislocation ultrasound absorption // Physical acoustic. M.: "Mir", 1969, v. 4, P. A, p. 261-321.

2. N.F. Mott. A theory of workhazdening of metal crystals // Phil. mag. 1952, v. 43, N 346, p. 1151-1178.

3. J. Fridel. Anomaly in the rigitity modulus of copper allous for small concentration // Phil. mag. 1953, v. 44, N 351, p. 444-448.

4. J. Weertman. Internal friction of metal single crystals // J. Appl. Phys.1955, v. 26, N 2, p. 202-210.

5. J.S. Koehler. The influence of dislocations and impurities on the damping and the elastic constants of metal single crystals. Imperfections in nearly perfect crystals. New York, 1952, p. 197-216.

6. V.I. Alshits, V.L. Indenbom. Dynamic drag of dislocations // Usp. Fiz. Nauk. 1975, v. 115, N 3, p. 3-39 (in Russian).
7. V.I. Alshits. Phonon wind" and dislocation drag // FTT. 1969, v. 11, N 8, p. 2405-2407.

8. T. Ninomiya. Dislocation vibration and phonon scattering // J. Phys. Soc. Japan. 1968, v. 25, N 3, p. 830-840.

9. V.I. Alshits, Yu.M. Sandler. Flutter mechanism of dislocation drag // Phys. Stat. Sol. (b). 1974, v. 64, $\mathrm{N} 1$, p. 45-49.

10. V.I. Alshits. Raman scattering as a cause of dislocation drag // FTT. 1969, v. 11, N 5, p. 1336-1344.

11. V.I. Startsev, V.Ya. Ilyichev, V.V. Pustovalov. Plasticity and strength of metals and alloys at low temperatures. M.: "Metallurgiya", 1975, 328 p.

12. R. Truell, Ch. Elbaum, B. Chik. Ultrasound methods in solid state physics. M.: "Mir", 1972, 307 p.

13. S.P. Nikanorov, B.K. Kardashov. Elasticity and Dislocation Inelasticity of Crystals. M.: "Nauka", 1985, $256 \mathrm{p}$.

14. V.S. Postnikov. Inernal friction in metals. M.: "Metalurgia", 1969, 330 p.

15. M.A. Krishtal, S.A. Golovin. Internal friction and metal structure. M.: "Metalurgia", 1976, 375 p.

16. A.A. Botaki, A.A. Vorobev, V.A. Ulyanov. Radiation physics of ionic crystals. M.: "Atomizdat", 1980, 208 p.

17. E.Yu. Gutmanas, E.M. Nadgorny, A.V. Stepanov. Study of the motion of dislocations in sodium chloride crystals // FTT. 1963, v. 5, N 4, p. 1021-1026.

18. V.B. Parijsky, S.V. Lubenets, V.I. Startsev. Mobility of dislocations in monocrystals of potassium bromide // FTT. 1966, v. 8, N 4, p. 1227-1238.

19. S.V. Lubenets, V.I. Startsev. Mobility and interaction of dislocations with an impurity in crystals $\mathrm{KCL}: \mathrm{Ba}^{2+} / / F T T .1968$, v. 10, N 1, p. 23-28.

20. V.B. Parijsky, A.I. Tretyak. Temperature dependence of the mobility of dislocations in $\mathrm{KBr}$ single crystals // FTT. 1967, v. 9, N 9, p. 2457-2468.

21. V.B. Parijsky, A.I. Landau, V.I. Startsev. On the discontinuous motion of dislocations in LiF single crystals // FTT. 1963, v. 5, N 5, p. 1377-1385.

22. V.B. Parijsky, A.I. Landau, V.M. Borzhkovskaya. Spontaneous dislocation jumps in LiF single crystals // FTT. 1963, v. 5, N 9, p. 2570-2575.

23. G.A. Ermakov, E.M. Nadgorny. The mobility of dislocations in $\gamma$-irradiated $\mathrm{NaCl}$ crystals. High speed range // FTT. 1971, v. 13, N 2, p. 513-519.

24. I.V. Gectina, F.F. Lavrentiev, V.I. Startsev. Temperature dependence of the viscous drag coefficient of dislocations in zinc crystals // Physics of metals and metallography. 1974, v. 37, N 6, p. 1274-1277.

25. O.I. Datsko. Dislocation internal friction of a material with vacancies in pulses of a weak magnetic field // FTT. 2002, v. 44, N 2, p. 289-290.

26. O.I. Datsko, V.I. Alekseenko, A.L. Brusov. Effect of weak magnetic field pulses on grain-boundary relaxation in aluminum // FTT. 1999, v. 41, N 11, p. 1985-1987.

27. E.V. Darinskaya, A.A. Urusovskaya, A.A. Bespalko, G.I. Gering. Investigation of the dynamics of dislocations during deformation of $\mathrm{NaCl}$ crystals by ultrashort irradiation pulses in an electron beam // FTT. 1982, v. 24, N 3, p. 940-941. 
28. E.V. Darinskaya, I.P. Makarevich, Yu.I. Meshcheryakov, V.A. Morozov, A.A. Urusovskaya. Study of the mobility of edge dislocations in $\mathrm{LiF}$ and $\mathrm{NaCl}$ crystals under pulsed electron-beam loading // FTT. 1982, v. 24, N 5, p. 1564-1566.

29. E.V. Darinskaya,

A.A. Urusovskaya, V.N. Opekunov, G.A. Abramchuk, V.A. Alekhin. Study of viscous dragging of dislocations in $\mathrm{LiF}$ crystals by the mobility of individual dislocations // FTT. 1978, v. $20, \mathrm{~N} 4$, p. $1250-1252$.

30. E.V. Darinskaya, A.A. Urusovskaya, V.I. Alshits, V.A. Alekhin, A.A. Shemyakova. Features of deformation under pulsed loading of CsJ crystals and the dynamics of individual dislocations // FTT. 1981, v. 23, N 6, p. 1751-1755.

31. E.V. Darinskaya, A.A. Urusovskaya. Temperature dependence of viscous drag of dislocations in $\mathrm{LiF}$ crystals // FTT. 1983, v. 25, N 6, p. 1892-1894.

32. E.V. Darinskaya, A.A. Urusovskaya, V.I. Alshits, Yu.I. Meshcheryakov, V.A. Alekhin, R. Voska. Study of the mobility of "fast" dislocations and the kinetics of impulsive deformation under shock loading of $\mathrm{NaCl}$ crystals // FTT. 1983 , v. 25, N 12, p. 3636-3641.

33. V.I. Alshits, E.V. Darinskaya, M.V. Koldaeva, R.K. Kotowski, E.A. Petrzhik, P.K. Tronczyk. Experimental studies and computer simulations of magnetoplastic effect // Pol. J. Appl. Sci. 2016, v. 2, p. 21-24.

34. V.I. Alshits, E.V. Darinskaya, M.V. Koldaeva, R.K. Kotowski, E.A. Petrzhik, P.K. Tronczyk. Dislocation kinetics in nonmagnetic crystals: a look through a magnetic window // Uspekhi Fizicheskikh Nauk. 2017, v. 60(30), p. 305-318 (in Russian).

35. V.I. Alshits, M.V. Koldaeva, E.A. Petrzhik, A.Yu. Belov, E.V. Darinskaya. Determination of the positions of impurity centres in a dislocation core in a $\mathrm{NaCl}$ crystals from magnetoplastisity spectra // JETP Letters. 2014, v. 99, N 2, p. 82-88.

36. V.I. Alshits, E.V. Darinskaya, M.V. Koldaeva, E.A. Petrzhik. Electric stimulation of magnetoplastisity hardening in crystals // JETP Letters. 2008, v. 88, N 7, p. 428-434.

37. V.I. Alshits, E.V. Darinskaya, M.V. Koldaeva, E.A. Petrzhik. Electric amplification of the magnetoplastic effect in nonmagnetic crystals // Journal of applied physics. 2009, v. 105, p. 1-9.

38. V.I. Alshits, E.V. Darinskaya, M.V. Koldaeva, E.A. Petrzhik. Resonanse magnetoplastisity in ultralow magnetic fields // JETP Letters. 2016, v. 104, N 5, p. 353-364.

39. V.I. Alshits, E.V. Darinskaya, M.V. Koldaeva, E.A. Petrzhik. Anisotropic resonant magnetoplastisity of $\mathrm{NaCl}$ crystals in the Earth's magnetic field // Physics of the solid state. 2013, v. 55, N 2, p. 358-366.

40. V.I. Alshits, E.V. Darinskaya, E.A. Petrzhik. S.A. Erofeeva. On the relation between thermaly activated and magnetically stimulated prosesses during dislocation movement in InSb crystals in a magnetic field // JETP. 2006, v. 102, N 4, p. 646-651.

41. Yu.I. Golovin. Magnetoplastic effects in solids // Physics of the solid state. 2004, v. 46, N 5, p. 769803.

42. V.I. Alshits, E.V. Darinskaya, M.V. Koldaeva, S.A. Minyukov, E.A. Petrzhik, V.A. Morozov,
V.M. Kats, A.A. Lukin, A.E. Naimi. Resonanse magnetoplastisity in EPR scheme under ultralow magnetic fields // Bulletin of the Russian Academy of Science. 2014, v. 78, N 10, p. 1041-1051.

43. S.V. Lybenets, V.I. Startsev. Mobility and interaction dislocations with impurity in crystals KCL: $\mathrm{Ba}^{2+} / /$ FTT. 1968, v. 10, N 1, p. 23-28.

44. V. Naundorf, K. Lücke. Mechanisms of Internal Friction in Solids. M.: "Nauka", 1976, 91 p.

45. Yu.F. Boiko, S.V. Lubenets, L.S. Fomenko, N.M. Fedirenko. About study of dynamic properties of dislocations by the shock loading sample method // I $z v$. Vyzov. Fizika. 1978, N7, p. 129-131 (in Russian).

46. T. Suzuki, A. Ikushima, M. Aoki. Acoustic attenuation studies of the frictional force on a fast moving dislocation // Acta met. 1964, v. 12, N 11, p. 1231-1240.

47. W.P. Mason. Drag of dislocations due to termal losses of the phonon-phonon type // J. Appl. Phys. 1964 , v. 35, N 9, p. 2779-2781.

48. W.P. Mason, A. Rosenberg. Phonon and electron drag coefficient in single-crystal aluminiun // Phys. Rev. 1966, v. 151, N 2, p. 434-441.

49. G. Leibfried. Uber den einflus therutins engeregter schallwellen auf die plastische deformation // Zs. Phys. 1950, v. 127, N 1, p. 344-351.

50. T. Kaneda. Frictional force on a fast moving dislocation in cooper and its dilute allows // $J$. of the Phys. Soc. of Japan. 1970, v. 28, N 5, p. 1205-1211.

51. G.A. Alers, D.O. Tompson. Dislocation contribution to the modulus and damping in copper at megacycle frequencies // J. Appl. Phys. 1961, v. 32, N 2, p. 283-293.

52. R.M. Stern, A. Granato. Damped dislocation resonance in copper. Internal friction and defects in metals. M.: "Metallurgiya", 1965, p. 149-191.

53. W.G. Johnston, J.J. Gilman. Dislocation velocities, dislocation densities and plastic flow in lithium fluoride crystals // J. Appl. Phys. 1959, v. 30, N 2, p. 129-144.

54. N.P. Kobelev, Y.M. Soifer, V.I. Alshits. The relation between viscous and relaxation components of dislocation damping of the high-frequency ultrasound in the copper // FTT. 1979, N 4 (21), p. 1172-1179.

55. V.I. Alshits, A.M. Petchenko. About temperature dependency of dynamic dislocation drag. Mechanisms of internal frictions in solids. M: "Nauka", 1976, p. 29-33.

56. L.A. Yakovlev. Investigation of the frequency and amplitude dependences of the dislocation absorption of ultrasound in aluminum // Acoustic journal. 1965, v. XI, N2, p. 239-242.

57. R. Hasiguti, N. Igata, M. Shimotomai. Frictional forces of moving dislocation in iron and iron allow crystals // J. of the Phys. Soc. of Japan. 1968, v. 24, p. 424-425.

58. R.L. Roderick, R. Truell. The measurement of ultrasonic attenuation in solids by the pulse technique and some results in steel // J. Appl. Phys. 1952, v. 23, N 2, p. 267-279.

59. W. Mason, MacDonald. Damping of dislocation in niobium by phonon viscosity // Journ. of Appl. Phys. 1971, v. 42, N 5, p. 1836-1842. 
60. P. Pal-Val, V. Platkov, V. Startsev. Temperature dependence of the dislocation drag constant in antimony // Phys. stat. sol. 1976, v. 38, p. 383-391.

61. P.P. Pal-Val, V.Ya. Platkov. Dislocation highfrequency internal friction in bismuth single crystals in the interval $4.2-300 \mathrm{~K} / /$ Fizika Nizkikh Temperatur. 1977, v. 3, N 10, p. 1302-1313.

62. L.G. Merculov. Absorption of ultrasonic waves in some alkali halide crystals // Acoustic journal. 1959, v. 5, N 4, p. 432-439.

63. L.G. Merculov, L.A. Yakovlev. Ultrasound studies of deformed $\mathrm{NaCl}$ crystals // Acoustic journal, 1960, v. 6, N 2, p. 244-251.

64. L.G. Merculov, R.V. Kovalionok, E.V. Konovodchenko. Temperature dependence of the absorption of ultrasonic waves in $\mathrm{NaCl}$ crystals // FTT. 1971, v. 13, N 4, p. 1171-1177.

65. E.V. Korovkin, Ya.M. Soifer. The effect of dislocations on the attenuation of ultrasound in $\mathrm{NaCl}$ crystals // FTT. 1971, v. 13, N 12, p. 3709-3710.

66. N.P. Kobelev, Ya.M. Soifer. Viscous drag of dislocations in alkali halide crystals // FTT. 1976, v. 18, N 4, p. 1073-1076.

67. F. Fanti, J. Holder, A.V. Granato. Viscous drag on dislocation in $\mathrm{LiF}$ and $\mathrm{NaCl} / / J$. Acoust. Soc. Amer. 1969, v. 45, N 6, p. 1356-1366.

68. A. Hikata, J. Deputat, C. Elbaum. Dislocation interactions with phonons in sodium chloride in the temperature range 77-300 K // Phys. Rev. 1972, v. 6, N 10, p. 4008-4013.

69. A. Hicata, B. Chick, C. Elbaum, R. Truell. Dislocation damping in sodium chloride // Appl. Phys. Let. 1963, v. 2, N 1, p. 5-6.

70. A.V. Granato, J. de Clerk, R. Truell. Dispersion of elastic waves in sodium chloride // Phys. Rev. 1957, v. 108, N 3, p. 895-896.

71. A.M. Petchenko, V.I. Mozgovoi, A.A. Urusovskaya. Viscous drag of dislocations in $\mathrm{NaCl}$ single crystals at temperatures $77-300 \mathrm{~K} / /$ FTT. 1988, v. 30, N 10, p. 2992-2995.

72. V.I. Mozgovoi, A.M. Petchenko, A.F. Sirenko. Investigations of the damping of dislocations of acoustic $\mathrm{NaCl}$ crystals by ultrasonic pulsed echo-method // Acoustic journal. 1990, v. 36, N 1, p. 101-105.

73. A.M. Petchenko. Dispersion of the velocity of longitudinal ultrasonic waves in $\mathrm{NaCl}$ crystalls // FTT. 1990 , v. 2, N 11, p. 3362-3365.

74. A.M. Petchenko. The effect of strain on the velocity dispersion of elastic waves in sodium chloride // Ukrainian journal of physics. 1990, v. 35, N 9, p. $1385-$ 1387.

75. A.M. Petchenko, D.L. Stroilova, V.I. Mozgovoy. Synthesis and investigation of optical materials. Kharkiv: "Institute of Monocrystals", 1987, p. 133-139.

76. A.A. Urusovskaya, V.I. Mozgovoi, A.M. Petchenko. Effect of pre-strain rate on stress relaxation in single $\mathrm{NaCl}$ crystals // JETP Letters. 1988, v. 14, N 13, p. 1176-1178.

77. A.A. Urusovskaya, A.M. Petchenko, V.I. Mozgovoi. Speed sensitivity of stress relaxation in $\mathrm{NaCl}$ single crystals // FTT. 1989, v. 31, N 1, p. 195-199.

78. A.M. Petchenko, V.I. Mozgovoi, A.F. Sirenko, A.A. Urusovskaya. Return of attenuation and ultrasound speed during stress relaxation in sodium chloride single crystals // FTT. 1989, v. 31, N 6, p. 127-130.

79. A.A. Urusovskaya, A.M. Petchenko, V.I. Mozgovoi. The influence of strain rate on stress relaxation // Phys. stat. sol. (a).1991, v. 125, N 1, p. 155-160.

80. H. Koizumi, I. Iwasa, M. Kakumoto, T. Suzuki. Study of dislocations in CsJ by simultaneous measurements of ultrasonic velocity and attenuation // J. Journ. of Appl. Phys. 1986, v. 25, p. 52-54.

81. A.M. Petchenko, D.L. Stroilova, A.A. Urusovskaya. Temperature dependence of the coefficient of damping of dislocations in single CsJ crystals // FTT. 1988. v. 30, N 11, p. 3455-3460.

82. A.M. Petchenko, D.L. Stroilova, A.A. Urusovskaya, O.M. Smirnova. Dropping in cesium iodide crystals under various deformation conditions // FTT. 1990. v. 32, N 5, p. 1390-1393.

83. A.M. Petchenko. The study of relaxation processes in CsJ acoustic method // Ukrainian journal of physics. 1990. v. 35, N 12, p. 1834-1837.

84. A.M. Petchenko, D.L. Stroilova. Ultrasonic relaxation at drooping in CsJ // FTT. 1991, v. 33, N 3, p. $938-940$.

85. A.M. Petchenko. Dislocation absorption of ultrasound in elastically deformed CsJ crystals // FTT. 1991, v. 33, N 5, p. 1541-1544.

86. A.M. Petchenko. The effect of static loading on the attenuation of ultrasound in CsJ at different temperatures // Ukrainian journal of physics. 1991, v. 36, N 5, p. $770-773$.

87. M.A. Krishtal, S.A. Golovin, I.V. Troitskij. Study of the parameters of the dislocation structure of copper by the ultra-sound pulse method // Phys. Metals and Metal Science. 1973, v. 35, N 3, p. 632-639.

88. Kh.M. Khalilov, A.I. Agaev. Ultrasound absorption in $\mathrm{KCl}$ single crystals in the megahertz frequency range // Izv. AN Azerbajdg. SSR. 1966, N 2, p. 82-86.

89. Kh.M. Khalilov, A.I. Agaev. Dislocation absorption of ultrasound in deformed $\mathrm{KCl}$ crystals // FTT. 1971, v. 9, N 9, p. 2729-2731.

90. V.M. Andronov, A.M. Petchenko, V.I. Startsev. Temperature dependence of the coefficient of dislocation drag in potassium chloride at temperatures of 77-413 K // Acoustic journal. 1975, v. 21, N 4, p. 502507.

91. V.M. Andronov, A.M. Petchenko. Ultrasound attenuation in deformed single crystals // Acoustic journal. 1976, v. 22, N 1, p. 1-4.

92. A.M. Petchenko. Dislocation with phonon in $\mathrm{KCl}$ crystals // Functional Materials. 2000. v. 7, N 1, p. 94-97.

93. O.M. Petchenko, G.O. Petchenko. Phonon drag of dislocations in $\mathrm{KCl}$ crystals with various dislocation structure states // Ukrainian journal of physics. 2010, v. 55, N 6, p. 716-721.

94. G.A. Petchenko, A.M. Petchenko. Influence of elastic stresses and temperature on the dislocation unpinning from the stoppers in $\mathrm{KCl}$ crystals // Functional Materials. 2015, N 3, p. 293-298.

95. G.A. Petchenko, A.M. Petchenko. Thermal activation analysis of the dislocation unpinning from stop- 
pers in $\mathrm{KCl}$ crystals // Bullrtin of V.N. Karazin National University. 2015, N 23, p. 28-31.

96. O.M.M. Mitchel. Drag of dislocation in LiF // J. Appl. Phys. 1965, v. 36, N 12, p. 2083-2084.

97. A.M. Petchenko, V.I. Startsev. Temperature dependence of the drag coefficient of dislocations in $\mathrm{LiF}$ crystals // FTT. 1974, v. 16, N 12, p. 3655-3559.

98. A.M. Petchenko, A.F. Sirenko. The effect of plastic deformation on the frequency dependence of internal friction in LiF crystals // FTT. 1975, v. 17, N 11, p. 3373-3375.

99. A.M. Petchenko. Interaction of dislocations with phonons in LiF crystals // Crystallography. 1992, v. 37, N 2, p. 458-462.

100. A.M. Petchenko, G.A. Petchenko. Features of ultrasonic absorption in LiF crystals with varying dislocation density // Bullrtin of V.N. Karazin National University. 2009 , v. 865 , N 12, p. 39-44.

101. G.A. Petchenko, A.M. Petchenko. The study of the dislocation resonance in $\mathrm{LiF}$ crystals under the influence of the low-dose X-irradiation // Functional Materials. 2010, v. 17, N 4, p. 421-424.

102. G.O. Petchenko. Acoustic studies of the effect of X-ray irradiation on the dynamic drag of dislocations in LiF crystals // Ukrainian journal of physics. 2011, v. 56, N 4, p. 339-343.

103. G.A. Petchenko. Study of dislocation loss of ultrasound in irradiated $\mathrm{LiF}$ single crystals in the range of radiation doses 0...400 P // Problems of Atomic Science and Technology. 2012, N 2(78), p. 36-39.

104. G.A. Petchenko. Dynamic damping of dislocations in the irradiated LiF crystals // Functional Materials. 2012, v. 19, N 4, p. 473-477.

105. G.A. Petchenko. Study of dynamic and structural characteristics in irradiated LiF crystals // Problems of Atomic Science and Technology. 2013, N 2(84), p. 55-59.

106. G.A. Petchenko. Research of the preliminary deformation and irradiation effect on the viscous damping of dislocation in LiF crystals // Functional Materials. 2013, v. 20, N 3, p. 315-320.

107. G.O. Petchenko, O.M. Petchenko. Research of the elastic wave velocity dispersion in X-ray-irradiated LiF crystals // Ukrainian journal of physics. 2013, v. 58, N 10, p. 974-979.

108. G.O. Petchenko, O.M. Petchenko, S.M. Boiko. The investigation of X-ray irradiation on elastic, dynamical and structural characteristics of strained LiF crystals // Problems of Atomic Science and Technology. 2018, N 2(114), p. 25-28.

109. G.O. Petchenko, O.M. Petchenko, S.M. Boiko. The investigation of X-ray irradiation effect on the mobility of dislocations in LiF crystals // Problems of Atomic Science and Technology. 2018, N 5(117), p. 1620.

110. V.Ya. Platkov, V.P. Efimenko, V.I. Startsev. Study of some dynamic characteristics of dislocations in potassium bromide crystals by the method of internal friction // FTT. 1967, v. 9, N 10, p. 2799-2803.

111. V.P. Matsokin, G.A. Petchenko. Viscous dislocation drag in $\mathrm{KBr}$ crystals at 77-300 K // Fizika Nizkikh Temperatur. 2000, v. 26, N 7, p. 705-710 (in Russian).

112. G.A. Petchenko. Phonon damping of dislocations in potassium bromide crystals at different dislocation density values // Functional Materials. 2000, v. 7, N 4(2), p. 785-789.

113. G.A. Petchenko. Study of ultrasound absorption by dislocations in $\mathrm{KBr}$ single crystals under low static stresses // Functional Materials. 2001, v. 8, N 3, p. 483-487.

114. A.M. Petchenko, G.A. Petchenko. Features of resonance absorption of longitudinal ultrasound in strained crystals $\mathrm{KBr}$ at temperature variations // Functional Materials. 2007, v. 14, N 4, p. 475-479.

115. G.A. Petchenko, A.M. Petchenko. Effect of crystal pre-straining on phonon damping of dislocations // Functional Materials. 2008, v. 15, N 4, p. 481-486.

116. A.M. Petchenko, G.A. Petchenko. The dislocation resonance absorption of ultrasound in $\mathrm{KBr}$ crystals at low temperatures // Functional Materials. 2009, v. 16, N 3, p. 253-257.

117. V.M. Chernov. Mobility of dislocations in crystals with centers of pinning // FTT. 1973, v. 15, N 4, p. 1159-1166.

118. G.A. Petchenko, S.S. Ovchinnikov. Effect of the preliminary deformation and irradiation on the optical absorption in LiF crystals // Problems of Atomic Science and Technology. 2014, N 2(90), p. 29-33.

119. G.A. Petchenko, A.M. Petchenko. Dependence of electronic color center concentration on the state of irra-diated LiF crystal dislocation structure // Problems of Atomic Science and Technology. 2015, N 2(96), p. 25-28.

120. A. Smakula. Uber Erregung und Entfarbung lichtelektrisch leitender Alkalihalogenide // Z. Physik. 1930, N 9-10(59), p. 603-614.

121. A. Smakula, P. Avakiant. Color centers in cesium halide single crystals // Phys. Rev. 1960, N 6, p. 2007-2014.

122. D.L. Dexter. Absorption of light by atoms in solids // Phys. Rev. 1956, N 101, p. 48-55.

123. V.M. Lisitzyn. Radiation solid state physics. Tomsk: "Izdatelstvo Tomskogo Politekhnicheskogo Universiteta", 2008, 172 p. (in Russian).

124. M.V. Galustashvili, M.G. Abramishvili, D.G. Driaev, V.G. Kvachadze. Effect of magnetic field on the radiation hardening LiF crystals // FTT. 2011, N 53(7), p. 1340-1342 .

125. T. Klempt, S. Schweiser, K. Schwartz, et al. Magnetic resonance unvestigation of the dynamics of $\mathrm{F}$ centers in LiF // Solid State Communications. 2001, N 119, p. 453-458. 


\section{ОБЗОР ОСНОВНЫХ РЕЗУЛЬТАТОВ, ПОЛУЧЕННЫХ МЕТОДОМ \\ АМПЛИТУДНО-НЕЗАВИСИМОГО ВНУТРЕННЕГО ТРЕНИЯ \\ НА МЕТАЛЛАХ И ИОННЫХ КРИСТАЛЛАХ}

А.М. Петченко, Г.А. Петченко, С.Н. Бойко

Произведен анализ основных результатов, полученных в области исследования динамики дислокаций с использованием метода амплитудно-независимого внутреннего трения на разных объектах исследования металлах и щелочно-галоидных кристаллах. Рассмотрены результаты проверки струнной дислокационной теории Гранато-Люкке и квантово-механической теории динамического торможения дислокаций АльшицаИнденбома для указанных материалов. Выполнен аналитический обзор работ, направленных на изучение релаксационных и термически активируемых процессов в кристаллах. Выявлены перспективные направления для дальнейших экспериментальных работ по данной проблематике.

\section{ОГЛЯД ОСНОВНИХ РЕЗУЛЬТАТІВ, ОДЕРЖАНИХ МЕТОДОМ АМПЛІТУДНО-НЕЗАЛЕЖНОГО ВНУТРІШНЬОГО ТЕРТЯ НА МЕТАЛАХ ТА ІОННИХ КРИСТАЛАХ}

\section{О.М. Петченко, Г.О. Петченко, С.М. Бойко}

Проведено аналіз основних результатів, одержаних в області дослідження динаміки дислокацій з використанням методу амплітудно-незалежного внутрішнього тертя на різних об'єктах дослідження - металах і лужно-галоїдних кристалах. Розглянуто результати перевірки струнної дислокаційної теорії Гранато-Люкке і квантово-механічної теорії динамічного гальмування дислокацій Альшиця-Інденбома для вказаних матеріалів. Зроблено аналітичний огляд робіт, спрямованих на вивчення релаксаційних і термічно активованих процесів у кристалах. Виявлено перспективні напрямки для подальших експериментальних робіт за даною проблематикою. 